Karaelmas Fen ve Mühendislik Dergisi

Dergi web sayfasi: http://fbd.beun.edu.tr

DOI: $10.7212 \% 2 F z k u f b d . v 8 i 2.1201$
Araştırma Makalesi

Geliş tarihi / Received : 08.11.2017

Kabul tarihi / Accepted : 11.12.2017

\title{
Al ve Yerleştir Robot Otomasyonu İçin Bir Çerçeve Çalışması
}

\section{A Frame Study for Pick-and-Place Robot Automation}

\author{
Mustafa Ayyıldız ๑ \\ Düzce Üniversitesi, Teknoloji Fakültesi, Makine ve İmalat Mühendisliği Bölümü, Düzce, Türkiye
}

\section{$\ddot{O} z$}

Robotik uygulamalarda görme destekli sistemlerin kullanımı giderek yaygınlaşmakta ve görüntü işleme metodu kullanılarak robotik destekli al ve yerleştir uygulamaları geliştirilmektedir. Bu çalışmada, al ve yerleştir robotun imalatı yapılmış ve üretim hattı üzerindeki ürünlerin anlık resim bilgileri bir kamera yardımıyla alınmıştır. Robotun çalışma alanı içerisine giren ürünlerin çalışma hattından alınarak çıkış hattına yerleştirilmesi için robotun yörünge planlaması yapılmıştır. Bunun için ürünün ağırlık merkezinin koordinatları ve üretim hattında bulunduğu konumun koordinatları bulunarak robota gönderilmiştir. Robota gelen koordinat bilgilerine göre al ve yerleştirme işlemi gerçekleştirmektedir. Bu çalışma ile otomasyon sektöründeki küçük ve orta ölçekli işletmeler için ihtiyaca yönelik istenen tüm uyarlamaların görüntü işleme fonksiyonlarıyla kolaylıkla yapılabilecek bir sistem geliştirilmesi amaçlanmaktadır. Özellikle seri üretim yapılan plastik şişe, boru gibi parçaların form kontrolü, en boy ölçümü gibi kontrolleri, eksik parça kontrolü, modele göre montaj hatası kontrolü gibi uygulama alanı olan sektörlere adapte edilebileceği düşünülmektedir.

Anahtar Kelimeler: Al ve yerleştir robot, Otomasyon, Robotik

\begin{abstract}
The use of systems based vision is becoming increasingly widespread in robotic applications and image processing methods are used to develop robotic assisted pick-and-place operations. In this study, the pick-and-place robot was manufactured and product information on the production line was taken with the help of a camera. By designing the robot's trajectory planning, the products entering the robot working area were taken from the working line and placed in the exit line. For this, the coordinates of the center of the product and the coordinates of the position in the production line were found and sent to the robot. According to the coordinate information were performed pick-and-place operations. This study was aimed to develop a system that can easily be done with image processing functions for demand-oriented adaptations for small and medium-sized businesses in the automation sector. Particularly mass-produced parts such as plastic bottles and pipes are considered to be able to be adapted to sectors that have application fields such as form control, length measurement control, missing part control, and assembly error control by model.
\end{abstract}

Keywords: Pick-and-place robot, Automation, Robotic

\section{Giriş}

Endüstri alanındaki teknolojik gelişmeler, ürün ve hizmetlerden talep edilen kalite standartlarını giderek yükseltmektedir. Üretim hızı ve bu hıza bağlı olarak üretilen malzemenin standartlara uygunluğunun kontrolünün yapılması için gereken süreç hızının da artması bir gereklilik olmuştur. İstenilen kaliteyi elde ederken, maliyetleri de en aza indirebilecek ve yeniliklere açı kontrol sistemlerin uygulamaya konulması zorunlu hale gelmiştir. Her parçanın el veya gözle tek tek ölçülmesi ve ayrıştırılması ekonomik

*Sorumlu yazarın e-posta adresi: mayyldz@hotmail.com

Mustafa Ayy1ldiz (D orcid.org/0000-0002-4534-6713 olmamaktadır. Dolayısıyla birçok malzemenin üretim ve kontrolü de otomasyonla gerçekleştirilmesi gerekmektedir (Shiakolas vd. 2002).

Endüstriyel robotların yoğun olarak kullanıldığı seri imalat hatlarında yer aldığ 1 uygulamalardan biride al ve yerleştir işlemleridir. Robotik uygulamalarda görme destekli sistemlerin kullanımı giderek yaygınlaşmakta ve görüntü işleme metodu kullanılarak robotik destekli al ve yerleştir uygulamaları geliştirilmektedir (Kristensen vd. 2001; Rousseau vd. 2001; Bone ve Capson 2003). Al ve yerleştir uygulamalarında, bir robot kolunun dağınık nesneleri alması ve onları istenilen konuma düzgün bir biçimde yerleştirmesi için nesnelerin bir konveyör bandındaki konumunu veya nesnelerin yerleştirileceği koordinatların bilinmesi gerekmektedir. 
Nesnenin konum bilgisini elde etmek için kullanılan yaygın yaklaşımlardan biri bilgisayar görme tabanlı yöntemdir (Otsu 1979). Literatürdeki yapılan çalışmalara bakıldığında, Hwang ve arkadaşaları (2016) bir konveyör bant üzerinde hareket eden cisimlerin tanınması ve koordinatlarının elde edilmesi için bir sistem önermişlerdir. Bu sistem, 2 boyutlu görüntülü bir görüntü işleme sistemi, nesneleri görüntü işleme algoritmalarıyla tanımak ve konumlandırmak için düşük maliyetli 2 boyutlu mono CCD kameraya sahiptir. Farklı konumdaki değişik nesnelerin al ve yerleştir işlemleri için hareket planlamasını oluşturmuşlardır. Lin ve arkadaşları (2016) bir endüstriyel manipülatör tarafindan gerçekleştirilen al ve yerleştirme görevlerinde gerekli olan nesneden elde edilen 3 boyutlu konum bilgisini almak için bir stereo kamera sistemi kullanmışlardır. Deneysel sonuçlar, gelişmiş görme sistemi ile donatılmış bir endüstriyel manipülatörün otomatik al ve yerleştir görevlerini başarılı bir şekilde gerçekleştirebildiğini göstermiştir.

$\mathrm{Bu}$ çalışmada, görme destekli al ve yerleştir robotu, üretim hattı üzerindeki ürünlerin anlık resim bilgileri bir kamera yardımıla alarak, bunu anlamlı bir formata dönüştürmektedir. $\mathrm{Bu}$ anlamlı format, ürünün geometrik özelliklerini içeren; alan, çevre, kompaktlık, uzama, dikdörtgensellik ve dairesellik gibi unsurlardır. Robotun çalışma alanı içerisine giren ürünlerin çalı̧̧ma hattından alınarak başka bir çalışma hattına yerleştirilmesi için robotun yörünge planlaması yapılmıştır. Bunun için ürünün ağırlık merkezinin koordinatları ve üretim hattında bulunduğu konumun koordinatları bulunarak robota gönderilmiştir. Robota gelen koordinat bilgilerine göre al ve yerleştirme işlemi gerçekleştirilmektedir.

\section{Gereç ve Yöntem}

$\mathrm{Bu}$ çalışma, donanım ve yazılım olarak iki bölümden oluşmaktadır. Donanım bölümü; robot, kamera ve çalışma hattı için bant konveyörlerden oluşmaktadır. Robot, kartezyen yapıda olarak tasarlanmı̧s ve kamera çalışma hattının üzerine entegre edilmiştir. Konveyör bantlardan biri giriş hattı, diğeri işe çıkış hattıdır. Robotun hareket mekanizması, doğrusal triger hareket modülleri kullanılmış ve hibrit step motorlar ile sürülmüştür. Hareket kontrol kartı ile hibrit step motorlar geliştirilen yazılım yardımıyla kontrol edilmektedir.

Yazılım bölümünde ise kameranın, robotun çalışma hattına giren ürünlerin anlı resim bilgisi alacak olan Windows tabanlı bir arayüz tasarlanmıştır. Bu arayüz kamera ile robot arasındaki iletişimi sağlayacak ve ürünün geometrik özelliklerinin çıkarılmasında gerekli olan görüntü işleme fonksiyonlarını içermektedir. $\mathrm{Bu}$ arayüzün diğer bir işlevi ise ürünün koordinatlarına göre robotun kinematik hesaplamalarını yapmasıdır. Donanım kısmındaki hareket kontrol kartının kontrolü de bu yazılım ile gerçekleştirilerek, robotu kontrol edecek bir yazılım ile tasarlanmıştır.

\subsection{Al ve Yerleştir Robot Mekanizmasının Tasarımı ve Prototipi}

Prototip olarak tasarlanan al ve yerleştir robot mekanizması, 3 serbestlik dereceli olup kartezyen yapıdadır. Al ve yerleştir robotun her ekseni doğrusal hareket etmekte ve tahrik motoru olarak 6,2 $\mathrm{Nm}$ tutma torkuna sahip hibrit step motorlar kullanılmıştır. Doğrusal hareket modülü, 64x64 alüminyum 6063 profilden imal edilmiş, Z26-5M-30F triger kayış ve kasnak ile iletim sağlayan, $15^{\prime}$ lik lineer ray ve dar alçak araba ile iletimi taşıyan, hareket hızı $5 \mathrm{~m} /$ sn ve bir turu $130 \mathrm{~mm}$ yol alarak, pozisyon konumlama hassasiyeti $0.01 \mathrm{~mm}$ olarak tasarlanmıştır. Doğrusal hareket modüllerinin $\mathrm{X}, \mathrm{Y}, \mathrm{Z}$ eksenlerindeki çalışma mesafeleri $500 \mathrm{~mm}$ olarak belirlenmiş ve her eksen limit anahtar ile sınırlandırılmıştır. Şekil 1'de al ve yerleştir mekanizmasının prototipi gösterilmiştir.

Konveyör bantların sürülmesi için $6,2 \mathrm{Nm}$ tutma torkuna sahip hibrit step motor kullanılmıştır. Hibrit step motorları sürmek için 8 A'lik yükü taşıyabilen bir sürücü kullanılmıştır. $\mathrm{Bu}$ sürücü motorun yön kontrolüne izin vermektedir. Çalışma giriş hattındaki konveyör bantta kullanılan motorun yönü sola ve çıkış hattındaki konveyör banttaki motorun yönü sağa dönecek şekilde belirlenmiştir. Adlink PCI-8154 hareket kontrol kartı ile al ve yerleştir robottaki 3 ayrı hibrit step motor sürücü kullanılarak kontrol edilmiştir. Çalışma hattında bulunan konveyör banttaki hibrit step motorlar ise hareket kontrol kartına tek giriş olacak şekilde bağlanmıştır. Çalışma hattında bulunan giriş konveyörü bant üzerine Autonics BRP200-DDTN-P fotoelektrik sensör entegre edilmiş ve gelen ürün bilgisini vermektedir. Tutma işlemi ise vantuz tutucu ile gerçekleştirilmektedir.

\subsection{Görüntü Alma Birimi ve Arayüz Tasarımı}

Prototipi yapilan al ve yerleştir robotu, çalı̧̧ma hattı üzerindeki ürünlerin anlık resim bilgileri USB 3.0 destekli ve saniyede 60 kare yakalama özelliğine sahip IDS UI-3250ML- C kamera yardımıyla alarak, bunu anlamlı bir formata dönüştürmektedir. Bu anlamlı format, ürünün geometrik özelliklerini içeren; alan, çevre, kompaktlık, uzama, dikdörtgensellik ve dairesellik gibi unsurlardır. Robotun çalışma alanı içerisine giren ürünlerin çalı̧̧ma 
giriş hattından alınarak çalışma çıkış hattına yerleştirilmesi için robotun yörünge planlaması gerekmektedir. Bunun için ürünün ağırlık merkezinin koordinatları ve çalışma hattında bulunduğu konumun koordinatları bulunarak robota gönderilmektir. Robota gelen koordinat bilgilerine göre al ve yerleştirme işlemi gerçekleştirilmiştir. $\mathrm{Al}$ ve yerleştir robot mekanizmasının kontrolü, görüntü işleme modülü ve konveyörlerin kontrolü için tasarlanan yazılım ile sistemin entegre çalışması sağlanmaktadır. Şekil 2'de görüntü işleme modülü, al ve yerleştir robot kontrolü için tasarlanan arayüzler gösterilmektedir. Tasarlanan arayüz Visual Studio 2015'de Basic dilinde programlanmıştır.

Görüntü işleme modülünün işlem sırası aşağıdaki verilmektedir;

Adım 1: Giriş hattı konveyör bant üzerinde bulunan geometrik parçalar sensörün algılama alanına girdiği zaman konveyör durmaktadır. Kamera duran konveyör üzerindeki geometrik parçanın resmini yakalar. Alınan resmin çözünürlüğü 160x120 pikseldir (Şekil 3a). Sonra alınan
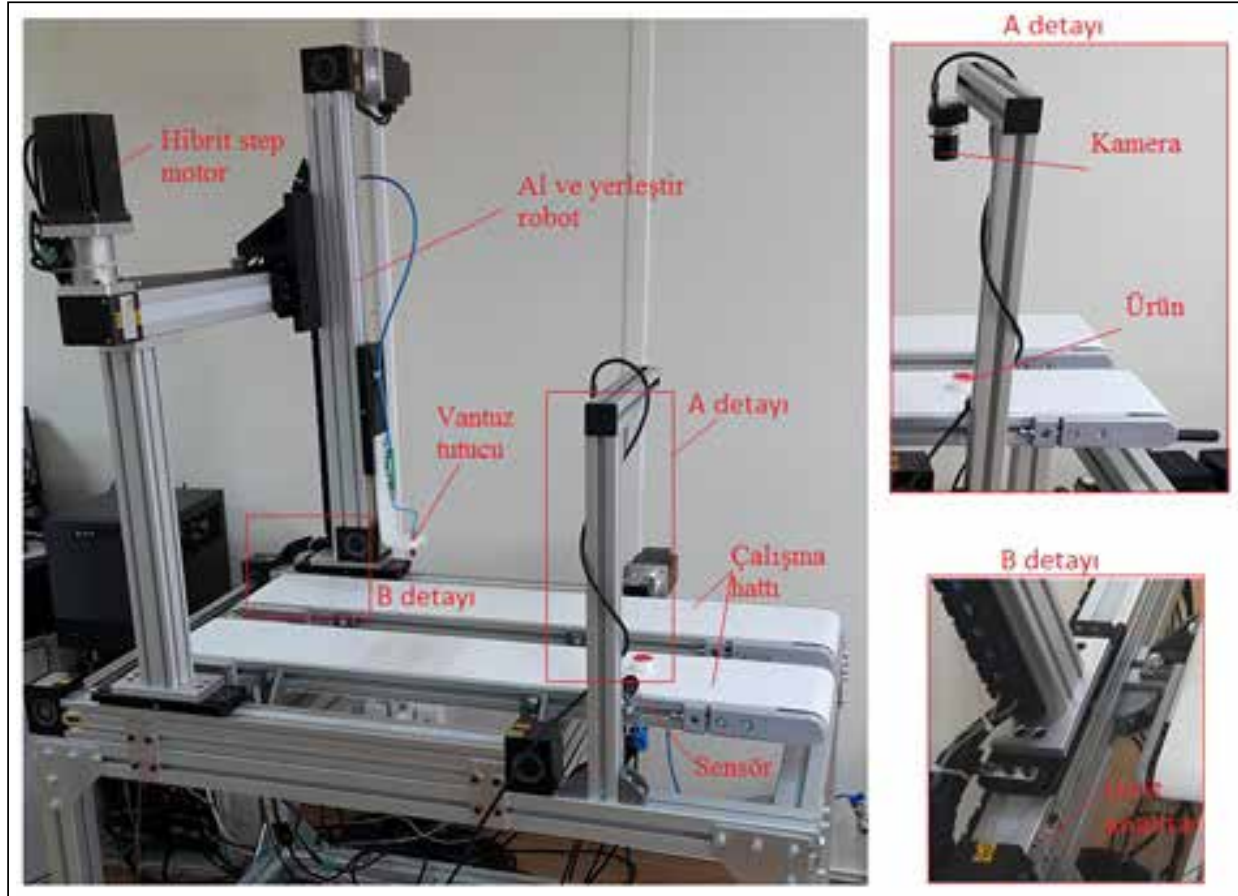

Şekil 1. Al ve yerleştir mekanizmasının prototipi.

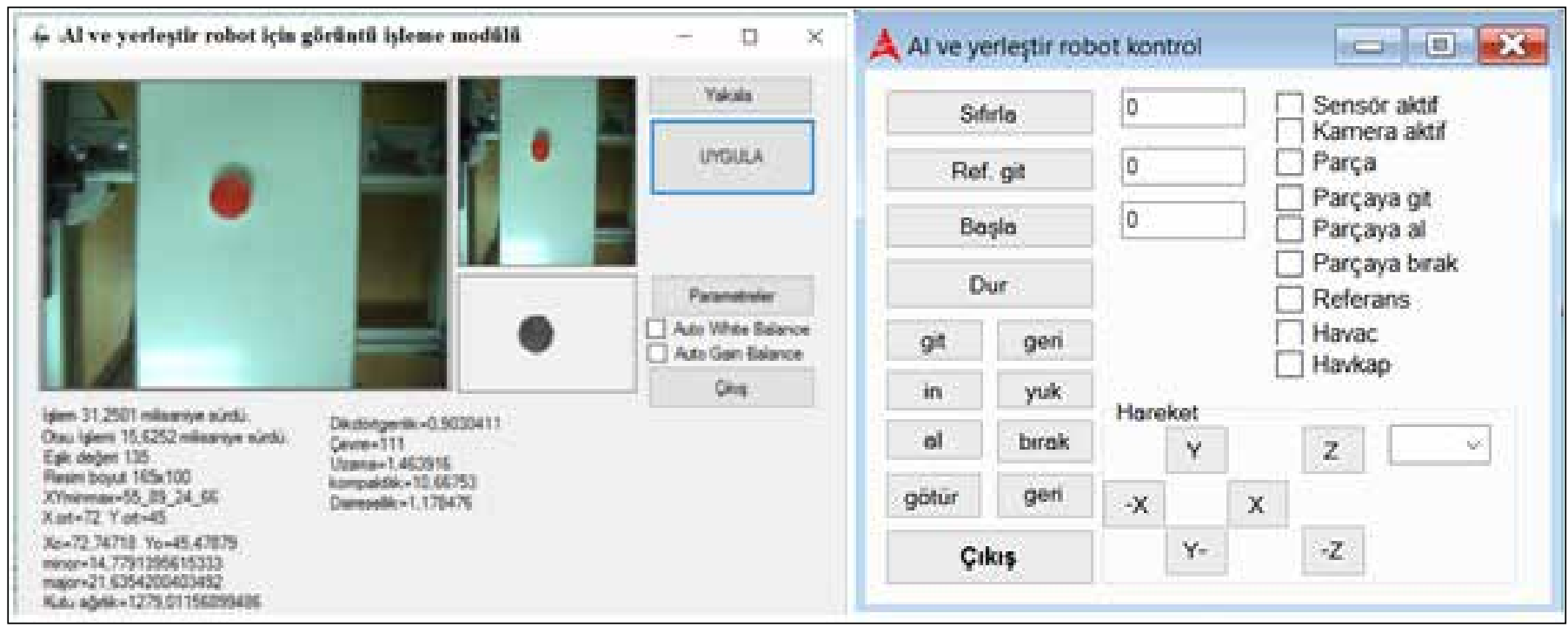

Şekil 2. Görüntü işleme modülü, al ve yerleştir robot kontrolü için tasarlanan arayüzler. 
resim 81x83 piksel boyutlarında kırpılır (Şekil 3b). RGB normunda olan kırpılan resim gri seviye ye çevrilir (Şekil 3c).

Adım 2: Otomatik eşikleme için Otsu metodu kullanılarak gri seviyeli resim ikili resme çevrilmiştir (Pratt 2007), (Şekil $3 d)$.

Adım 3: Farklı parçaların geometrik şekillerinin çıkarılması için alan, çevre, kompaktlık, uzama, dikdörtgensellik ve dairesellik gibi özelliklerinin tanımlanması gerekmektedir. İkili resmi g olarak varsayarsak, burada $g(m, n)=1$ geometrik şeklin pikselleri, $g(m, n)=0$ ise arka plan pikselleri olarak tanımlanır. Geometrik şeklin alanı (A) ikili resimdeki $\mathrm{g}(\mathrm{m}, \mathrm{n})=1$ değerlerin toplamına eşittir (Costa ve Junior 2009). Alan formülü Eşitlik 1'de verilmiştir.

$A=\sum_{i=1}^{m} \sum_{j=1}^{n} g(m, n)$

Eşitlik 1'de $m$ ve $n$ ikili resmin yükseklik ve genişliğini ifade etmektedir. $g(m, n)$ ikili resmin piksel değeridir (Şekil 4a). Geometrik şeklin çevresi $\left(\mathrm{P}_{c}\right)$ herhangi bir sınır pikselinden itibaren başlayıp geometrik şeklin kenar piksellerinin etrafında dönerek tekrardan bu sınır pikseline gelinceye kadarki piksellerin toplamıdır (Costa ve Junior 2009), (Şekil 4b). Kompaktlık $\left(\mathrm{C}_{\mathrm{k}}\right)$, geometrik şeklin konturlarının karmaşıklığını değerlendirmek için kullanılan bir şekil tanımlayıcısıdır.

Kompaktlığın minimum değerine sahip olan çoğu kompakt alan bir dairedir ve kompaktllı̆g $4 \pi$ değerine eşittir. Bu değer yaklaşık 12,56'dır (Hwang vd. 2016). Kompaktlık formülü Eşitlik 2' de verilmiştir.

$C_{k}=\frac{P_{c}^{2}}{A}$

Burada $\mathrm{P}_{\mathrm{c}}$ çevre, A geometrik şeklin alanıdır.

Geometrik şeklin sınırlarındaki iki pikseli bağlayan çizgi kiriş olarak ifade edilmektedir. Birçok geometrik şekil için en uzun kiriş uzunluğu bize geometrik şeklin özelliği hakkında bilgi vermektedir. Ĕger $\left(n_{1}, m_{1}\right)$ ve $\left(n_{2}, m_{2}\right)$ sınır pikselleri arasında kiriş uzunluğuna bakılırsa bu lc olarak tanımlanır ve Eşitlik 3'de gibi ifade edilir.

$l c=\sqrt{\left(m_{2}-m_{1}\right)^{2}+\left(n_{2}-n_{1}\right)^{2}}$

En uzun kiriş iki sınır pikselin tüm olası kombinasyonlarını inceleyerek ve mesafeleri karşılaştırarak bulunabilir. En
(A)

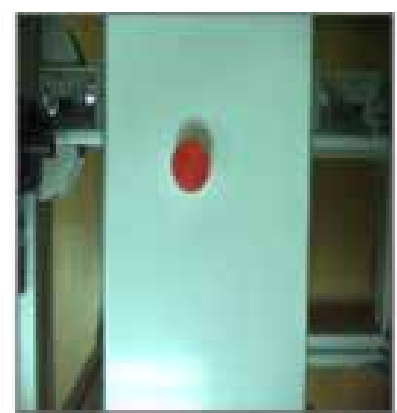

(B)

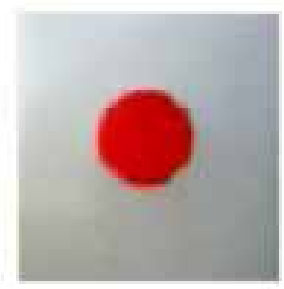

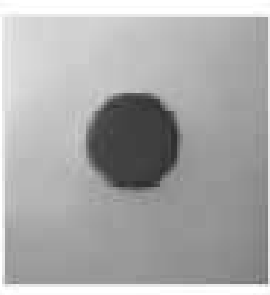

(C)

(D)

Şekil 3. Ön işlemler A) alınan resim, B) kırpılan resim, C) gri seviye ve D) otomatik eşikleme

(A)

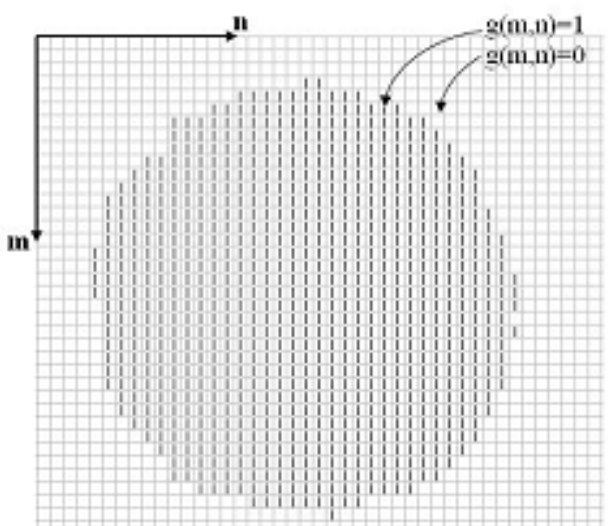

(B)

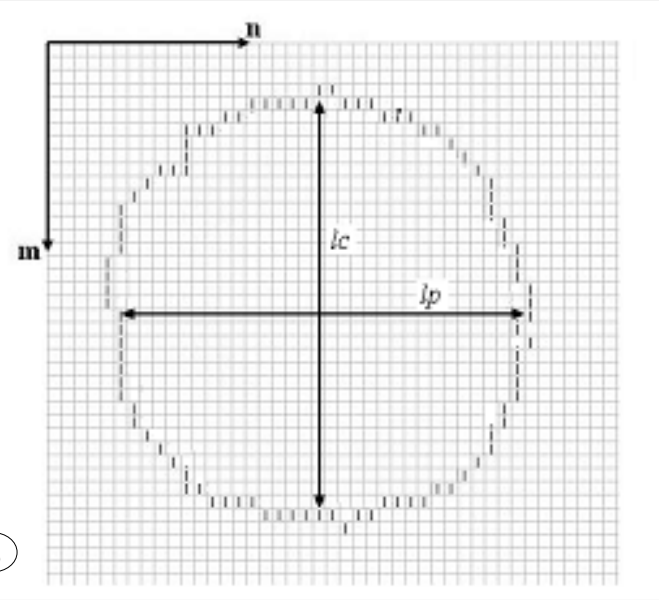

Şekil 4. İkili resim A) geometrik şeklin alanı ve B) çevresi, lc ve lp. 


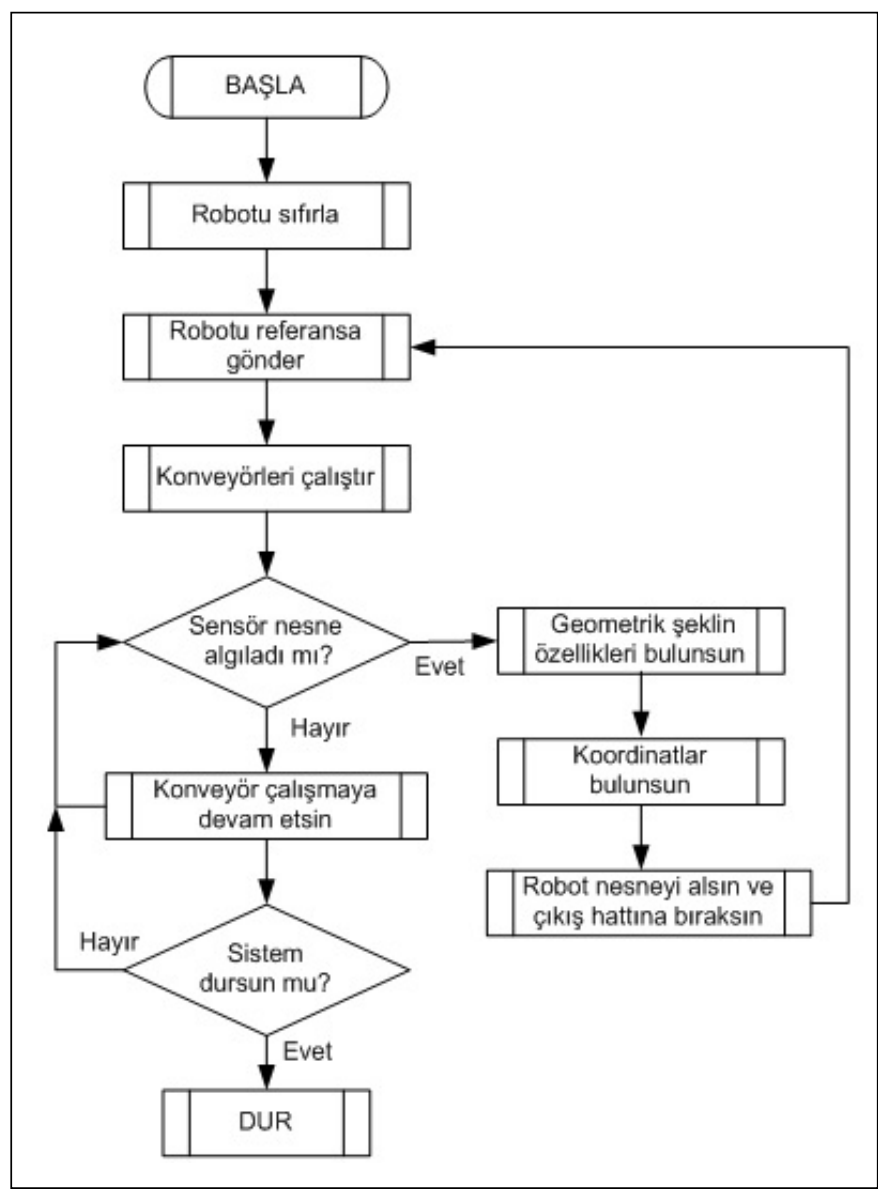

Şekil 5. Sistemin akı̧ diyagramı (Flow diagram of the system). uzun kirişe dik olan maksimum uzunluk lp bize ek olarak şekil bilgisini vermektedir. Bir geometrik şekilde uzama, lc/ lp en uzun kirişin en uzun dik kirişe oranı ile bulunmaktadır (Hwang vd. 2016), (Şekil 4b). Geometrik şeklin minimum sınırlayıcı çerçeve alanı $\left(\mathrm{A}_{\min }\right)$, geometrik şekle temas eden kenarlardan meydana gelen bir dikdörtgen olduğundan, lclp ile hesaplanabilir. Bir geometrik şeklin dikdörtgenliği $\left(\mathrm{R}_{\mathrm{d}}\right)$, geometrik şeklin alanının minimum sınırlayıcı çerçeve alanına oranı $\mathrm{A} / \mathrm{A}_{\min }$ ile tanımlanır. Bu oran 1 ise geometrik şekil dikdörtgen, küçük ise diğer şekillerdir. Geometrik şeklin daireselliği (Rn) Eşitlik 4'de verilmiştir (Costa ve Junior 2000; Ayyıldız ve Çetinkaya 2016).

$$
R n=\frac{4 \pi A}{P_{c}^{2}}
$$

Eşitlik 4'de A geometrik şeklin alanı, $\mathrm{P}_{\mathrm{c}}$ ise geometrik şeklin çevresini ifade etmektedir.

\subsection{Deneysel Uygulama}

Sistemin akış diyagramı Şekil 5'de verilmektedir. Al ve yerleştir robotun referans pozisyonu işlemi gerçekleşmesiyle çalışma hattındaki konveyörler çalışmaya başlamakta ve nesnenin sensörde algılanmasıyla ile görüntü işleme modülü aktif hale gelmektedir. Nesne, robotun çalı̧sma alanına girdiğinde konveyörler durmakta ve giriş hattında bulunan nesnenin koordinatları göre alma işlemi yapılarak çıkış hattındaki konveyöre bırakılmaktadır. Bırakma işlemi ardından

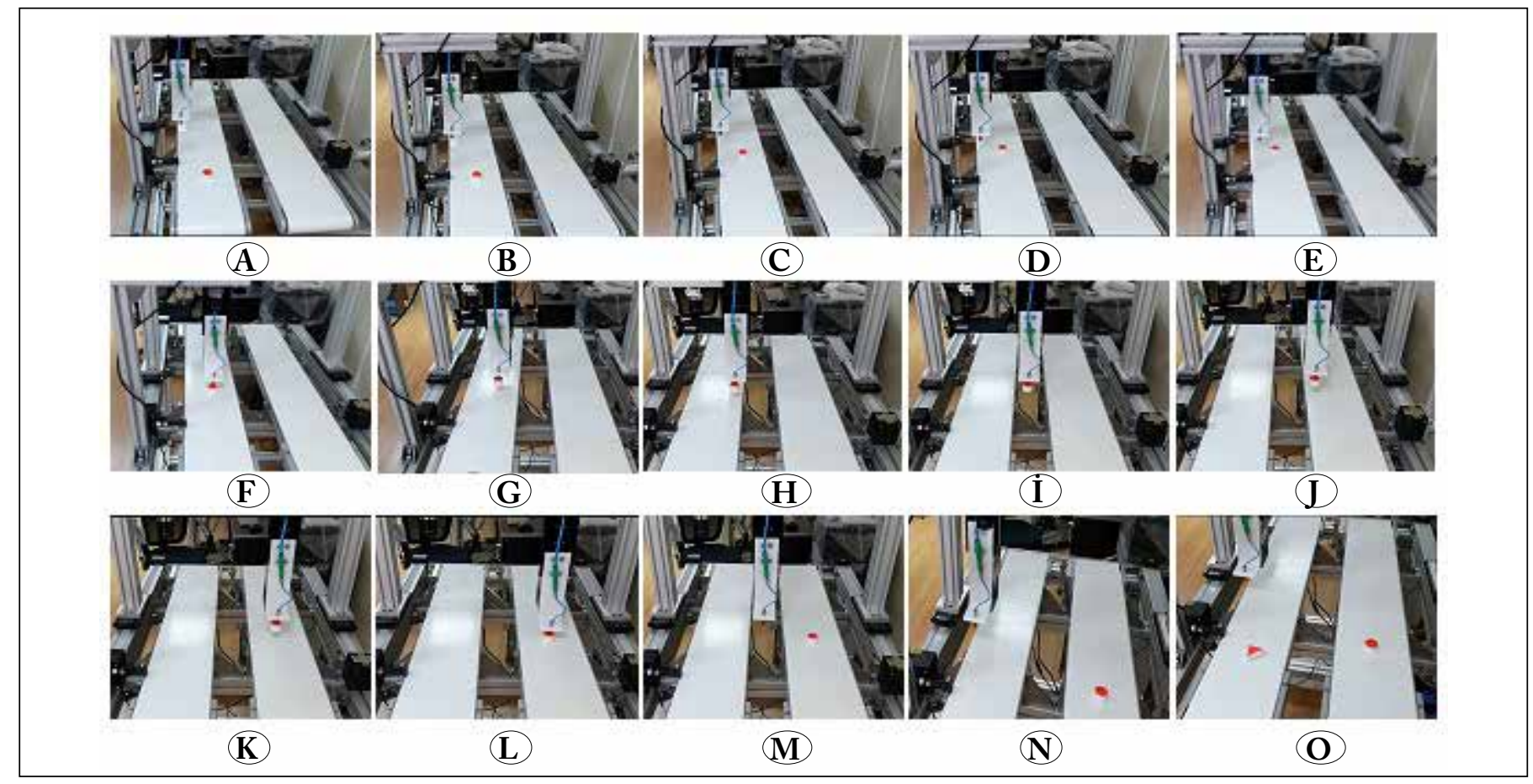

Şekil 6. Deneysel uygulama için bir dairesel nesnenin al ve yerleştirme işlemi. 
konveyörler tekrar çalışarak çevrim devam etmektedir. Şekil 2'de görüntü işleme modülü için tasarlanan arayüz ve görüntü işleme metotlarının uygulanması verilmektedir.

Şekil 6'da deneysel uygulama için bir dairesel nesnenin al ve yerleştirme işlemi gösterilmektedir. Al ve yerleştir robotun referans konumu Şekil 6a'da ve nesnenin sensör ile algilanarak görüntü işleme modülünün işleme girmesi, çalışma giriş hattındaki nesnenin hareketi Şekil 6b'de, nesnenin robotun çalışma alanına girerek çalışma hattının durması ve robotun nesnenin ağırlık merkezi koordinatlarına yönelmesi Şekil 6c'den Şekil 6f'ye kadar, nesnenin robot ile alınması ve çıkı̧̧ hattına yerleştirilmesi Şekil 6g'den Şekil 6l'ye kadar, robotun referans konumuna dönmesi ve çalışma hattının tekrar çalışması Şekil 6m'den Şekil 6n'ye kadar, Şekil 6o'da ise yeni nesnenin çalışma hattına girmesi gösterilmektedir.

\section{Sonuçlar}

$\mathrm{Bu}$ çalışma ile görüntü işleme modülü, al ve yerleştir robot mekanizmasının ve konveyörlerin kontrolü için tasarlanan yazılım geliştirilmişve sistemin entegre çalışması sağlanmıştır. Deneylerde ürünlerin anlık resim bilgileri yakalanarak ürünün geometrik özellikleri olan çevre, kompaktlık, uzama, dikdörtgensellik ve dairesellik gibi unsurlar çıkarılmıştır. $\mathrm{Bu}$ geometrik özelliklere göre ürünün ağırlık merkezi ve konveyör üzerindeki konum bilgileri bulunarak al ve yerleştir robot için koordinat bilgileri bulunmuştur. Geliştirilen bu sistem otomasyon sektöründeki ihtiyaçlara yönelik istenen tüm uyarlamaları görüntü işleme fonksiyonlarıla kolaylıkla yapılabilecek bir arayüz geliştirmiştir ve ilgili uygulama alanı olan sektörlere adapte edilebilecek yapıdadır.

\section{Kaynaklar}

Ayyıldız, M., Çetinkaya, K. 2016. Predictive modeling of geometric shapes of different objects using image processing and an artificial neural network. P I Mech Eng E-J Pro., DOI:0954408916659310, (2016).

Bone, GM., Capson, D. 2003. Vision-guided fixtureless assembly of automotive components. Robot Comput Integr Manuf., 19: 79-87.

Costa, LDF., Junior, RMC. 2000. Shape analysis and classification: Theory and practice. CRC Press, Inc. Boca Raton, FL, USA.

Hwang, YS., Wang, L., Lee, DH., Lee, JM. 2016. Vision based machine for pick-and-place operation. International Conference on Intelligent Manufacturing and Materials, Paper 49-54.

Kristensen, S., Estable, S., Kossow, M., Brösel R. 2001. Binpicking with a solid state range camera. Rob Auton Syst., 35: 143-151.

Lin, CC., Gonzalez, P., Cheng, MY., Luo, GY, Kao, TY. 2016. Vision based object grasping of industrial manipulator. In Advanced Robotics and Intelligent Systems (ARIS) International Conference on IEEE, Paper 1-5.

Otsu, N. 1979. A threshold selection method from gray-level histograms. IEEE Trans Syst Man Cybern Sys., 9(1): 62-66.

Pratt, WK. 2007. Digital image processing, PIKS Scientific Inside, Fourth Edition, John Wiley \& Sons, Inc., Hoboken, NJ, USA.

Rousseau, P., Desrochers, A., Krouglicof N. 2001. Machine vision system for the automatic identification of robot kinematic parameters. IEEE Trans Robot Autom., 17(6): 972978.

Selver, M., Akay, O., Alim, F., Bardak, S., Olmez, M. 2011. An automated industrial conveyor belt system using Image processing and hierarchical clustering for classifying marbleslabs. Robot Comput Integr Manuf., 27: 164-176, (2011).

Shiakolas, PS., Conrad, KL., Yih, TC. 2002. On the accuracy, repeatability, and degree of influence of kinematics parameters for industrial robots. Int. J Model Simul., 22(3): 1-10. 